Omni-Akuatika, 14 (3): 1-9, 2018
ISSN: 1858-3873 print / 2476-9347 online
Research Article
journal homepage: http://ojs.omniakuatika.net

\title{
The Chemical Composition of Gracilaria verrucosa Extract and its Utilization on Survival and Growth of Litopenaeus vannamei
}

\author{
Yudiana Jasmanindar ${ }^{1,2}$, Sukenda Sukenda ${ }^{3^{*}}$, Alimuddin Alimuddin ${ }^{3}$, Muhammad Zairin \\ Junior $^{3}$, Nur Bambang Priyo Utomo ${ }^{3}$
}

\author{
${ }^{1}$ Graduated School, Bogor Agricultural University, Bogor, West Java, Indonesia \\ ${ }^{2}$ Study Programme of Aquaculture, Faculty of Marine and Fisheries, Kupang, East Nusa Tenggara, Indonesia \\ ${ }^{3}$ Departement of Aquaculture, Faculty of Fisheries and Marine Science, Bogor Agricultural University, Bogor, \\ West Java, Indonesia \\ "Corresponding author: sukenda@ipb.ac.id
}

Received 24 July 2018; Accepted 25 September 2018; Available online 30 November 2018

\begin{abstract}
The Gracilaria genus is a potential source of natural and environmentally-friendly alternatives in improving the survival and growth of shrimp. This study aimed to identify immunostimulant molecules extracts Gracilaria verrucosa and evaluate the utilization of $G$. verrucosa extract as an immunostimulant in improving survival and growth of Litopenaeus vannamei. Seaweed extraction used ethyl acetate then formulated in the diets. The immunostimulant molecule in the G. verrucosa was analyzed. The shrimp were fed a test diet containing extract of $G$. verrucosa at a dose of $2 \mathrm{~g}^{\mathrm{kg}}{ }^{-1}$ or extract $G$. verrucosa-free diets for 42 days. Shrimps were fed diets containing extract with a specific duration. The observation on the survival and growth of $L$. vannamei was performed at the Laboratory after six weeks of treatment. Following, diets containing extract was tested in the field (pond shrimp farm) at the same dose of extract for 58 days. Shrimp was feed diets containing extract once a week, once in the early culture, and diet control, then the survival and growth shrimp were analyzed. Concentrations of sulfates and carbohydrates in G. verrucosa ethyl acetate-extract were $24.21 \%$ and $13.41 \%$, and crude protein $3.64 \%$. GC-MS pyrolysis results showed that G. verrucosa polysaccharide is similar to immunostimulant molecules. The survival of shrimp gave diets containing $G$. verrucosa extract formulation was higher than that of shrimps fed controls diet. The Shrimp fed diets extract had higher growth than shrimp fed control diets.
\end{abstract}

Keywords: Gracilaria, extract, polysaccharides, immunostimulant

\section{Introduction}

Gracilaria is a source of food for health. The Gracilaria genus is a source for the agar industry, as well as food for humans (Saraswaty et al., 2015). An alternative source of seaweed in aquaculture that is as a compound that can stimulate or regulate the immune system of shrimp (Tayag et al., 2010; Sivagnanavelmurugan et al., 2014). Seaweed Gracilaria can stimulate the immune system of shrimp, and increasing resistance to infection disease (Chen et al., 2012; Wongprasert et al., 2014). Natural immunostimulants derived from plants are safe for the environment and useful for stimulating the innate immune system of shrimp (Dangeubun et al., 2013).

Immunostimulants trigger the immune system by the presence of a pathogenassociated molecular pattern (PAMP), recognized by receptors in innate immune cells (Dalmo and Bøgwald, 2008). Contact elicited an immune response and changed the activity of the immune receptor component (Cerenius et al., 2008). This mechanism is known to exist in shrimp (Sritunyalucksana and Söderhäll, 2000; Cheng et al., 2005). PAMP component is present in bacterial cell walls, glucan, animal or plant extracts (Sakai, 1999; Kitikiew et al., 2013; Sivagnanavelmurugan et al., 2014). Sulfated polysaccharides were isolated from seaweed have molecular pattern recognized by the innate immune cells (Yeh and Chen, 2008; Sivagnanavelmurugan et al., 2014; Wongprasert et al., 2014). Characteristic of immunostimulant use for increasing immune shrimp is the identity of the material safe for shrimp and consumers. The bioactive properties may vary depending on such as the purity extraction product (Ale et al., 2011). The 
crude sulfated polysaccharides (SPs) from $G$. verrucosa has been reported for immunostimulator to shrimp (Jasmanindar et al., 2008). This present study, observed the $G$. verrucosa crude extract SPs formulated in the diet to enhanced resistance of shrimp against pathogen and growth.

Administration of immunostimulants through diet has been shown to increase innate defenses (non-specific immune) and increase resistance to certain pathogens (Sakai, 1999). Defense against disease attacks on shrimp depends on the innate immune system (Hoffmann et al., 1999). Besides that, booster application of immunostimulant (duration) is necessary because immunostimulant is a disease control measure in a short time, allowing for a given duration (Barman et al., 2013).

The application of diet extracts should be examined in the field to collect data on the utilization of $G$. verrucosa extract formulated in the diet. The most experiment of dietary immunostimulant of seaweed extract performed at controlled environment (in the laboratory). In the present study, we examined a diet extract given with a certain duration, on survival rate and growth (biomass) of white shrimp maintained in the laboratory and in the field.

\section{Materials and Methods}

\subsection{Seaweed and maceration materials}

Seaweed G. verrucosa was obtained from aquaculture ponds in the village of Muara Gembong, Bekasi ( $5^{\circ} 57^{\prime} 1.0^{\prime \prime}-6^{\circ} 2^{\prime}$ 24.5"S

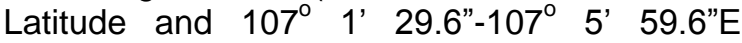
Longitude). The seaweed was sun-dried and extracted. Ethyl acetate used 3 parts for maceration of seaweed. The extraction solvent was distilled before use.

Isolation of polysaccharides used absolute ethanol with a ratio of $1: 4(\mathrm{v}: \mathrm{v})$, based on the method of Hidari et al. (2008).

\subsection{Extraction}

Dry G. verrucosa were macerated in 3 parts of ethyl acetate. The maceration was performed using a shaker at $110 \mathrm{rpm}$ for 48 hours. It was further filtered and evaporated at $50^{\circ} \mathrm{C}$. Crude extracts were stored in the $4^{\circ} \mathrm{C}$ before being analyzed and used.

\subsection{Isolation of sulfated galactan (SG)}

Isolation SG processed base on method Hidari et al. (2008). Briefly, G. verrucosa dried was ground and depigmentation, then stirred.
The extract was diluted with hot water $\left(100^{\circ} \mathrm{C}\right)$ and centrifuged. The pellet was reextracted and the supernatant filtered. The filtrate was stored overnight at $-10^{\circ} \mathrm{C}$. The supernatant was thawed and centrifuged. The non-gel was precipitated with 4 absolute ethanol volumes, then freeze-dried. The extract was stored in the $-10^{\circ} \mathrm{C}$ before being analyzed

\subsection{Analyze the chemical composition of $G$. verrucosa extract}

Carbohydrate concentration was measured by a phenol-sulfuric acid method with glucose as standard. Briefly, the extract was mixed with $5 \%$ phenol and concentrated sulfuric acid was added, then vortexed. The mixture was allowed to stand at room temperature for 10 minutes then cooled in an ice bath for 15 minutes for subsequent measurements at 490 $\mathrm{nm}$ absorbance.

Sulfate concentration analysis was performed using the spectrophotometer method, $\mathrm{K}_{2} \mathrm{SO}_{4}$ wasused as standard. The extract was hydrolyzed used $\mathrm{HCl} 2 \mathrm{~N}$. Solutiontransferred to make $10 \mathrm{~mL}$ volume and centrifuged. The supernatant was diluted with Milli $\mathrm{Q}$ water followed $\mathrm{HCl} 0,5 \mathrm{~N}$. Added $\mathrm{BaCl}$ gelatin, then retained for $30 \mathrm{~min}$ at room temperature. The absorbance was read at 550 $\mathrm{nm}$.

The proximate analysis of the extract used a standard method to determine the protein content of the dry weight of the extract.

The pyrolysis method of GC-MS was used to determine identities and weights of immunostimulant molecules contained in $G$. verrucosa extract. Data were identified used WILEY7 library database.

\subsection{Feeding trial diet containing G. verrucosa extract in the Laboratory}

L. vannamei juveniles $(6,74 \pm 0,1 \mathrm{~g})$ were obtained from Serang, Indonesia. Shrimps were maintained in a plastic container $(80 \mathrm{~L})$ with natural seawater and used the flowthrough system. Shrimps were kept in a fiberglass tank for acclimation prior to the experiments. There were four treatments (extract G. verrucosa-free control diet, feeding diets containing extract $G$. verrucosa once every week, feeding diets containing extract $G$. verrucosa every two weeks and only once fed diets containing extract $G$. verrucosa during feeding experiment). Maintenance of shrimp performed for we six weeks (42 days). The dose of $G$. verrucosa extracts used $2 \mathrm{~g} \mathrm{~kg}^{-1}$ has been tested in concentration determination (data not shown). The diets were given 2 times, with feeding rate $4 \%$. 
Growth was measured at the end feeding experiment (6th weeks), the weight gain of shrimp was determined by deducting the initial weight from final weight. The percentage weight gain and specific growth rate (SGR) were determined based on a formula by Immanuel et al., (2004)

Furthermore, the challenge test was conducted using $V$. harveyi as pathogen bacteria to assay survival rate of shrimp with the formula Amend (1981). After injection bacteria, shrimps were cultured for fourteen days.

2.6. Feeding trial diet containing extract in the field (pond shrimp farm)

This research was performed in the shrimp growth-out pond on a farm in Pinang Gading, Lampung, Indonesia for fifty-eight days(September-November, 2017). Shrimp with initial weight $4,70 \pm 0,20 \mathrm{~g}$, was kept in a floating net $\left(2 \times 1 \times 1 \mathrm{~m}^{3}\right)$. Diets containing extract $G$. verrucosa at dose $2 \mathrm{~g} \mathrm{~kg}^{-1}$ was given every once a week, and only once during maintenance. Shrimp were fed four times a day (06.00, 10.00, 14.00 and 17.00) at a feeding rate of $4 \%$. Feeding diets extract was performed for six weeks. Subsequent given commercial diets (feed shrimp vannamei grower) until harvest.

Shrimp production was evaluated at the end of the trial, considering the following parameters: weight gain, specific growth rate, feed conversion ratio (Goytortua-Bores at al., 2006). The survival rate at the end culture period was evaluated.

\subsection{Statistical analysis}

Data were analyzed as a design using the SPSS version 21 (IBM Corporation). Oneway ANOVA was performed. Duncan's multiple range test was used to identify significant differences in survival and growth performance, $\mathrm{P}<0.05$ was considered to be statistically significant.

\section{Results and Discussion}

3.1. Chemical composition of $G$ verrucosa extract

The chemical composition of $G$. verrucosa extracts presented in Table 1. The ethyl acetate extract was used as an immunostimulant formulated in the test feed.

Table 1. The chemical composition of $G$. verrucosa extract

\begin{tabular}{llllll}
\hline Sample & $\begin{array}{l}\text { Yield } \\
(\% \mathrm{w} / \mathrm{w})\end{array}$ & $\begin{array}{l}\text { Sulphate } \\
(\%)\end{array}$ & $\begin{array}{l}\text { Carbohydrate } \\
(\%)\end{array}$ & $\begin{array}{l}\text { Galactosa } \\
\left(\mathrm{mg}_{\mathrm{L}}^{-1}\right)\end{array}$ & $\begin{array}{l}\text { Protein } \\
(\%)\end{array}$ \\
\hline $\begin{array}{l}\text { Ethil acetate- } \\
\text { extract }\end{array}$ & $0,4-1,0$ & 24,21 & 13,41 & 0,46 & 3,64 \\
SG & 1,38 & 11,63 & 14,67 & $\mathrm{~nm}$ & $\mathrm{~nm}$ \\
\hline
\end{tabular}

$\mathrm{nm}$ : not measured

The proximate of ethyl acetate extract $G$. verrucosa (dry weight\%) has a crude lipid content of $81.32 \%$, ash $1.49 \%$, crude fiber $0.25 \%$, and BETN $13.14 \%$. Being a major concern in providing shrimp as a food that is safe for humans. Preventive materials used in dealing with shrimp disease need to be a concern for shrimp farmers. So the identification of the stimulant material used in shrimp diets needs to be known correctly (Meena et al., 2013).GCMS pyrolysis results showed that there were several chemical compositions in SG G. verrucosa which are 4-O- $\beta$-Dgalactopyranosyl, D-Galactose, Methyl 3,6anhydro- $\alpha$-D-galactopyranoside.

Some seaweed is a good source of food (Lahaye, 1991). In addition to a source of industrial materials. The Gracilaria genera have been identified as a source for the agar industry, a food source for humans as well as a source for the pharmaceutical industry (natural medicines) (Choi et al., 2007; Chen et al.,
2005). Until now the Gracilaria genera seaweed is known as immunostimulant (Wongprasert et al., 2014).

Extraction is performed to obtain a material in which there is an active ingredient as an immunostimulant. One molecule that is recognized by the shrimp immune system that can trigger an immune response in shrimp. Macroalga Gracilaria is a potential immunostimulant (Wongprasert et al., 2014; Chen et al., 2012; Hou and Chen, 2005; Yeh and Chen, 2009).

Red algae $G$. verrucosa widely cultivated in Indonesia, especially in Muara Gembong, Bekasi. This macroalga not only a source of agar but also has the potential as an immunostimulant in white shrimp (Jasmanindar et al., 2008). According to Wongprasert et al. (2014), the active ingredient in seaweed $G$. fisheri is sulfated galactan (polysaccharide sulfate) in particular, the complex structural content of galactose bound to sulfate in $\mathrm{C} 4$ of 
D-galactopyranose and C6 from Lgalactopyranoside. In Gracilaria there are such structures and sulfate bonds (Craigie et al. 1984; Melo et al. 2002).

The result of chemical composition analysis in the $S G$ isolated from $G$. verrucosa

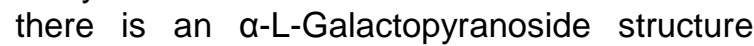
with molecular weight 178, and Methil 3,6-

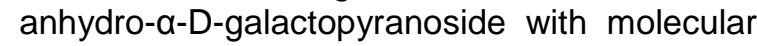
weight 176. And there is D-galactose with a molecular weight of 180 which is the structure that forms the agarose-oligosaccharide in the Gracilaria genera seaweed. This analysis also shows that SG derived from $G$. verrucosa is methylated agarobiose (due to the structure of D-galactose and 3,6-anhydro-Lgalactopyranose). The methyl derivatives present in SG are 4-O-galactose, this monosaccharide composition commonly present in the Gracilaria Genus (Souza et al., 2012; Wongprasert et al., 2014; Melo et al., 2002).

The amount of sulfate and galactose contained in the extraction material differs by type of Gracilaria and the method of extract used in extracting the active ingredient. According to Wogprasert et al. (2014) sulfate content of pure extraction (sulfated galactan) obtained from $G$. fisheri of $12.7 \%$ and total carbohydrate by $42.2 \%$. The extraction method used is cold water extraction and non-gelling polysaccharide. As much as 3\% SG obtained. Furthermore, other researchers obtained sulfate content of $4.8 \%$ to $11.7 \%$ ( $G$ corticata and $G$. cornea), while $G$. birdiae contained $6.4 \%$ sulfate content (Mazuder et al., 2002; Melo et al., 2002; Maciel et al., 2002). The sulfate content obtained in this study $24.21 \%$, which is the sulfate content of gel and non-gel G. verrucosa.

Sulfate obtained from Wongprasert et al. (2014) using the cold water extraction method seems to be the usual method used in producing non-gelling extracts from algal galactan (Lahaye, 2001). This active ingredient is a molecule in seaweed bound to polysaccharides. Polysaccharide sulfate present in fucoidan derived from brown seaweed has a bioactive function in humans one of them as an immunomodulator (Ale et al. 2011). The sulfate found in the Gracilaria red algae is bound to galactose as sulfated galactans proven to be an immunostimulator in tiger prawns that are resistant to white spot syndrome virus (WSSV) (Wongprasert et al. 2014). The sulfate group is principally present in C-4 of D-galactose and C-6 of L-galactose, which shows that $S G$ is a sulfated galactan (Wongprasert et al., 2014).

3.2. Growth and survival of shrimp fed diets containing extract with a specific duration and control diets.

The result of growth observation showed that there was a difference between shrimp given diets extract and shrimp fed control diets. The final weight of white shrimp kept for 42 days was 8.78 (A), 10.17 (B), 8.79 (C), and 11.04 (D). Increased growth and specific growth of white shrimp given diets extract once a week and once feeding of the extract at the beginning of the experiment was significantly higher than that of control shrimp (Table 2). It is assumed that extract $G$. verrucosa formulated in diets can improve the shrimp growth.

Incorporated immunostimulant into diets is the most method to stimulate the immune system (Azad et al., 2005). Immunostimulant substance extracted from seaweed $G$. verrucosa was formulated in the shrimp diets in order to increase resistance to infectious disease. Besides, it can improve the growth performance of shrimp.

Table 2. Growth and feed conversion of shrimp fed diets containing - G. verrucosa extract with a specific duration, and control diets for 42 days

\begin{tabular}{cccccc}
\hline Treatments & Wo $(\mathrm{g})$ & $\mathrm{Wt}(\mathrm{g})$ & $\mathrm{W}(\mathrm{g})$ & $\mathrm{WG}(\%)$ & SGR $(\% \mathrm{~g} / \mathrm{t})$ \\
\hline $\mathrm{A}$ & $6.82 \pm 0.17$ & $8.78 \pm 0.13$ & $1.96 \pm 0.05^{\mathrm{a}}$ & $28.77 \pm 1.34^{\mathrm{a}}$ & $0.60 \pm 0.02^{\mathrm{a}}$ \\
$\mathrm{B}$ & $6.68 \pm 0.04$ & $10.17 \pm 0.78$ & $3.49 \pm 0.80^{\mathrm{b}}$ & $52.31 \pm 12.10^{\mathrm{b}}$ & $1.00 \pm 0.19^{\mathrm{b}}$ \\
$\mathrm{C}$ & $6.74 \pm 0.04$ & $8.79 \pm 0.45$ & $2.05 \pm 0.46^{\mathrm{a}}$ & $30.49 \pm 6.83^{\mathrm{a}}$ & $0.63 \pm 0.13^{\mathrm{a}}$ \\
$\mathrm{D}$ & $6.73 \pm 0.09$ & $11.04 \pm 0.81$ & $4.31 \pm 0.80^{\mathrm{b}}$ & $64.10 \pm 11.99^{\mathrm{b}}$ & $1.17 \pm 0.18^{\mathrm{b}}$ \\
\hline
\end{tabular}

A (control); B (once a week); C (once every two weeks); D (only once at the beginning of maintenance). Mean $\pm S D$, different letters indicated significantly different (ANOVA test; $P<0,05$ and continued with Duncan test 


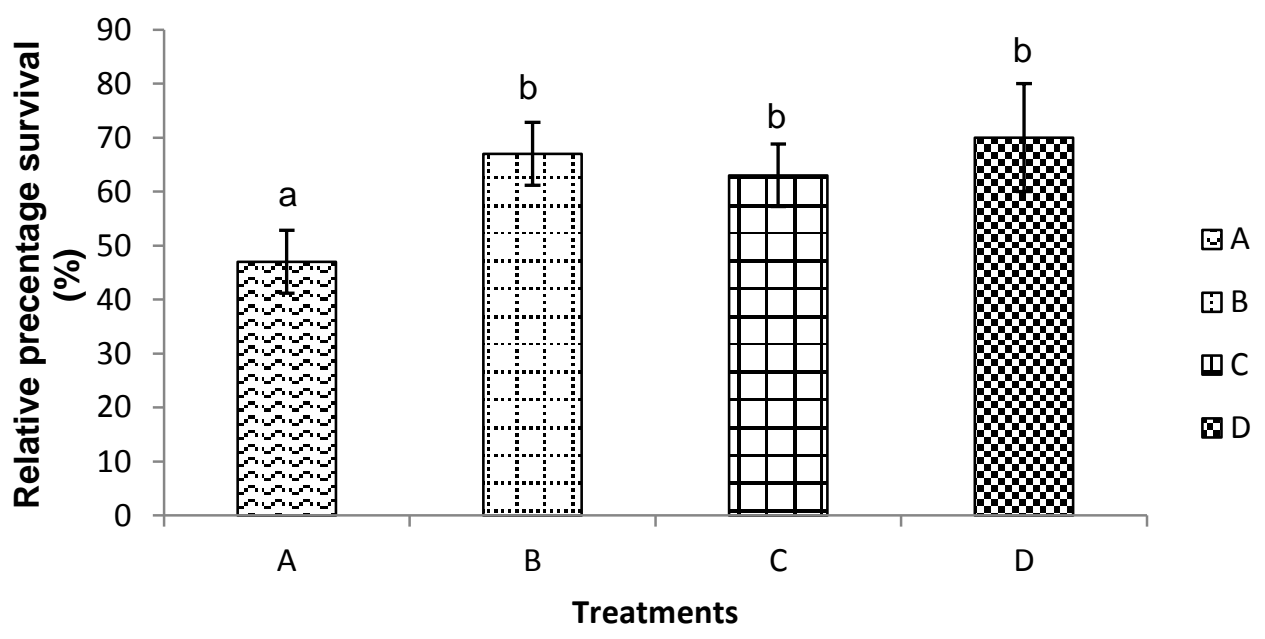

Fig 1. Relative survival rate (\%) of shrimp fed diets containing $G$. verrucosa extract with a specific duration (B (once a week); $\mathrm{C}$ (once every two weeks); $\mathrm{D}$ (only once at the beginning of maintenance), and control diets for 42 days (A). Data with different letters indicate the highly significant difference $(p<0.05)$.

Observations of relative survival were done after challenged with pathogenic $V$. harveyi. White shrimp fed extract diets with duration once a week or shorter can increase the immune system of shrimp that resistant to V. harveyi.

G. verrucosa extract can act as an immunostimulant, increasing immune system subsequent to the shrimp can survival from a bacterial infection. According to Cheng et al., (2004), L. vannamei received sodium alginate at $10 \mathrm{mg} \cdot \mathrm{g}^{-1}$ or more increased its immune ability and resistance from $V$. alginolyticus infection.

The survival rate of shrimp given dietary supplement in the form of yeast culture remains constant (Burgents et al., 2004).
Although there is a negative effect on the longterm administration of the material, in this study feeding diets extract with duration once a the week still had a positive impact on the survival and growth of shrimp.

In the present study, immunostimulant molecule in extract G.verrucosamight provoke innate immune cell of shrimp subsequent elicit an immune system, improve resistance shrimp against $V$. harveyi. Immunostimulant from seaweed used via oral administration was effective to enhance immune activity and resistance against diseases in shrimp (Yeh and Chen, 2009; Huang and Zhang, 2006; Liu et al., 2006, Kitikiew et al., 2013; Sivagnanavelmurugan et al., 2014)

Table 3. Growth and FCR in shrimp fed diets extractor control diet at shrimp farm

\begin{tabular}{ccccccc}
\hline Treatments & $\mathrm{Wo}(\mathrm{g})$ & $\mathrm{Wt}(\mathrm{g})$ & $\mathrm{W}(\mathrm{g})$ & $\mathrm{WG}(\%)$ & SGR & FCR \\
\hline $\mathrm{A}$ & $4.80 \pm 0.20$ & $19.48 \pm 0.62$ & $14.68 \pm 0.78$ & $306.79 \pm 27.76$ & $2.42 \pm 0.12$ & $0.96 \pm 0.09$ \\
$\mathrm{~B}$ & $4.77 \pm 0.18$ & $16.38 \pm 0.91$ & $11.61 \pm 1.09$ & $244.44 \pm 32.14$ & $2.13 \pm 0.16$ & $1.24 \pm 0.19$ \\
$\mathrm{C}$ & $4.55 \pm 0.19$ & $17.95 \pm 0.93$ & $13.40 \pm 1.08$ & $295.40 \pm 35.38$ & $2.37 \pm 0.15$ & $1.01 \pm 0.13$ \\
\hline
\end{tabular}

$\mathrm{A}$ (control), $\mathrm{B}$ (once a week), C ((only once at the beginning of cultivation)

Mean \pm SD, different letters indicated significantly different (ANOVA test; $P<0,05$ and continued with Duncan test 


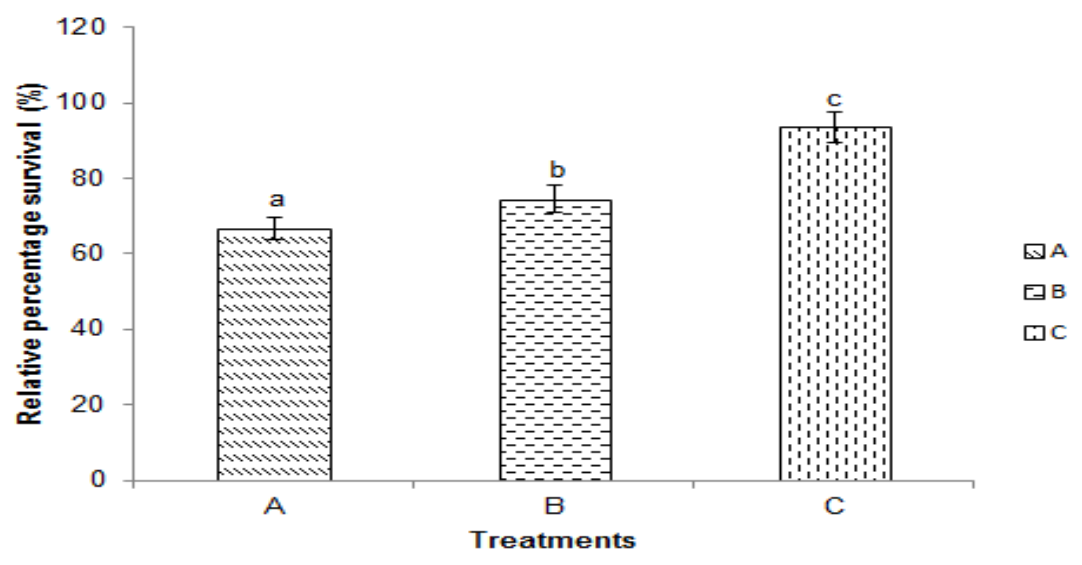

Fig. 2. The survival rate (\%) shrimp experiment in the field (A : feeding diet extract $G$. verrucosa-free, B : feeding diets containing extract $G$. verrucosa once every week, C : only once fed diets containing extract $G$. verrucosa during feeding experiment). Data with different letters indicate the highly significant difference $(p<0.05)$.

3.3. Survival and growth of shrimp fed diets containing $G$. verrucosa extract and control diets in the field

The parameter of water quality in the shrimp farm pond during feeding trial such as $\mathrm{pH} 7.5-8.0$; temperature $27-30^{\circ} \mathrm{C}$; salinity 28 30ppt; dissolved oxygen $4-6 \mathrm{mg} . \mathrm{L}^{-1}$, and nitrite 0.5-0.1 mg. $\mathrm{L}^{-1}$, remained within the recommended limits for culturing $L$. Vannamei.

Based on growth analysis there was no significant difference between treatments (Table 3). The relative survival analysis results of shrimp could be seen in Fig. 2. The shrimps fed only one extract for 58 days of maintenance had higher survival than control shrimp.

The productivity of ponds farm is related to the resulting biomass. Although there was no growth difference between shrimp given diets extract and shrimp has been given control diet, however, the shrimp weight given diets extract ranged from $244 \%$ to $295 \%$. The weight gain was quite significant when compared with the weight gain on the laboratory scale $(25.50$ - $64.10 \%)$. This showed that there were factors that influence the growth of shrimp at the pond.

Observation of relative survival of shrimp in this study was conducted on initial stocking and at harvest time, not based on the results of the challenge test. The analysis showed that the survival of shrimp given diets extracts was higher than the shrimp gave control diets.

Diseased caused mainly by Vibrio bacteria and viruses make commercial shrimp has suffered (Lo et al., 2003). V.harveyi is a serious pathogen of marine fish and invertebrates, particularly penaeid shrimp
(Austin and Zhang, 2006). Although no evidence diseases outbreaks during feeding trial, diets extract was able to support live shrimp in this study. Shrimp given immunostimulant in the long-term have a negative impact (Sung et al., 1994). However, in the present study, showed that feeding extracts were able to improve shrimp survival compared to control shrimp.

Intensive shrimp in Indonesia faced with the problem that constraints the development, there are water quality and production input such as diets. Qualification diets in the shrimp farm can improve the production (survival and growth). Previouslystudyshowed that extract seaweed G.verrucosa formulated in the diet could improve response immune and increase the resistance of shrimp against $V$. harveyi. The experiment diets containing extract in the field also shown can improve survival shrimp.

In the present study, G. verrucosa extract at concentration $2 \mathrm{~g} . \mathrm{kg}^{-1}$ challenged with the uncontrolled condition, to compare the data survival and growth with experiment at laboratory scale. The result showed that extract $G$. verrucosa could be applicated in the field. Diets containing extract $G$. verrucosa in the present study is alternative for improving survival and growth of L.vannamei culture. Besides, diets extract G.verrucosais favored by shrimp among other feed in the floating net.

\section{Conclusion}

Immunostimulant molecules in $G$. verrucosa seaweed extract have similarly to sulfated polysaccharides. Utilization of this extract formulated in shrimp feed can increase the survival rate of white shrimp both on the 
laboratory scale and in the field (shrimp farm). Shrimp fed diets extract at least at the beginning of culture has an increase in growth.

\section{Reference}

Ale, M.T., Mikkelsen, J.D., Meyer, A.S. 2011. Important Determinants for Fucoidan Bioactivity: A Critical Review of Structure-Function Relations and Extraction Methods for FucoseContaining Sulfated Polysaccharides from brown seaweeds. Mar. Drugs. 9:2106-2130. doi: $10.3390 / \mathrm{md} 9102106$

Angadiredja, J., Irawati, S., Kusmiyati. 1996. Potensi dan manfaat rumput laut di Indonesia dalam bidang farmasi. Prosiding Seminar Nasional Industri Rumput Indonesia. Jakarta, 1 - 10.

Austin, B., Zhang, X.H., 2006. Vibrio harveyi: a significant pathogen of marine vertebrates and invertebrates. Letters in Applied Microbiology 43:119-124.

Azad, I.S., Panigrahi, A., Gopal, C., Paulpandi, S., Mahima, C., Ravichandran, P. 2005. Routes of immunostimulation visa-vis survival and growth of Penaeusmonodon postlarvae. Aquaculture 248:227-234.

Burgents, J.E., Burnett, K.G., Burnett, L.E. 2004. Disease resistance of Pacific white shrimp, Litopenaeus vannamei, following the dietary administration of a yeast culture food supplement. Aquaculture 231: 1-8

Cerenius, L., Lee, B.K., Söderhäll, K. 2008. The proPO-system: pros and cons for its role in invertebrate immunity. Trends in Immunology. 29(6):263-272.

Chen, H.M., Zheng, L., Yan, X.J. 2005. The preparation and bioactivity research of agarooligosaccharides. Food Technology and Biotechnology 43(1):2936.

Chen, Y-Y., Sim, S.S., Chiew, S.L., Yeh, S-T., Liou. C-H., Chen, J-C. 2012. Dietary administration of a Gracilaria tenuispitata extract produces protective immunity of white shrimp Litopenaeus vannamei in response to ammonia stress. Aquaculture370-371:26-31.
Cheng, W., Liu, C.H., Kuo, C.M., Chen, J.C. 2005. Dietary administration of sodium alginate enhances the immune ability of white shrimp Litopenaeus vannamei and its resistance against Vibrio alginolyticus. Fish\&Shellfish Immunology 18:1-12.

Choi, H.G., Kim, Y.S., Kim, J.H., Lee, S.J., Park, E.J., Ryu, J., Nam, K.W. 2006. Effects of temperature and salinity on the growth of Gracilaria verrucosa and G. Chorda, with the potential for mariculture in Korea.Journal of Applied Phycology 18:269-277.

Craigie, J.S., Wen, Z.C., VanderMeer, J.P. 1984. Interspecific, intraspecific and nutritionally-determined variations in the composition of agars from Gracilaria spp. Botanica Marina 27(2):55-61.

Cruz-Suárez, L.E., Ricque-Marie, D., TapiaSalazar.M., McCallum, I.M., Hickling, D. 2001. Assessment of differently processed feed pea (Pisum sativum) meals and canola meal (Brassica sp.) in diets for blue shrimp (Litopennaeus stylirostris). Aquaculture 196:87-104.

Hidari, K.I.P.J., Takahashi, N., Arihara, M., Nagaoka, M., Morita, K., Suzuki, T. 2008. Structure and anti-dengue virus activity of sulfated polysaccharide from a marine alga. Biochemical and Biophysical Research Communication 376:91-95.

Dangeubun, J., Hardoko, Andayani, S., Risjani, Y. 2013. The Use of Active Compound in the Methanol Extract of Alstonia Acuminata for the Improvement of NonSpecific Immune System in Tiger Grouper (Epinephelus fuscoguttatus). Journal of Biology and Life Science 4(2):167-179.

Huang, X., Zhou, H., Zhang, H. 2006. The effect of Sargassum fusiforme polysaccharide extracts on Vibriosis resistance and immune activity of the shrimp, Fenneropenaeus chinensis. Fish \&Shellfish Immunology 20:750-757.

Hoffmann, J.A., Kafatoa, F.C., Janeway, Jr. C.A., Ekekowitz, R.A.B. 1999. Phylogenetic perspectives in innate immunity. Science, 284: 1313-1338. 
lyer, R., De Clerck, O., Bolton, J.J., Coyne, V.E. 2004. Morphological and taxonomic studies of Gracilaria and Gracilariopsis species (Gracilariales, Rhodophyta) from South Africa. South African Journal of Botany 70(4):521-539.

Jasmanindar, Y., Sukenda, Yuhana, M. 2008. Penggunaan ekstrak Gracilaria verrucosa untuk meningkatkan sistem ketahanan udang vaname Litopenaeus vannamei. Paper presented at Seminar Nasional Bioteknologi Akuakultur (August 14, 2008). IPB International Convention Center Bogor.

Kitikiew, S., Chen, J.C., Putra, D.F., Lin, Y.C., Yeh, S.T., Liou, C.H. 2013 Fucoidan effectively provokes the innate immunity of white shrimp Litopenaeus vannamei and its resistance against experimental Vibrio alginolyticus infection. Fish \&Shellfish Immunology34:280-290.

Labh, S.N., Shakya, S.R. 2014. Application of immunostimulant as an alternative to vaccines for health management in aquaculture. International Journal of Fisheries and Aquatic Studies 2(1):153156.

Lahaye, M. 2001. Developments in gelling algal galactans, their structure and physics-chemistry. Journal of Applied Phycology 13(2):173-184.

Liu, C.H., Yeh, S.P., Kuo, C.M., Cheng, W.T., Chou, C.H. 2006. The effect of sodium alginate on the immune response of tiger shrimp via dietary administration: activity and gene transcription. Fish \&Shellfish Immunology 21:442-452.

Lo, C.F., Chang, Y.S., Peng, S.E., Kou, G.H. 2003. Major viral diseases of Penaeus monodon in Taiwan. Journal of Fisheries Society of Taiwan 30:1-13.

Maciel, J.S., Chaves, L.S., Souza, B.W.S., Teixeira, D.I.A., Freitas, A.L.P., Feitosa, J.P.A., de Paula, R.C.M. 2008. Structural characterization of cold extracted fraction of soluble sulfated polysaccharide from red seaweed Gracilaria birdiae. Carbohydrate Polymers71:559-565.

Mazumder, S., Ghosal, P.K., Pujol, C.A., Carlucci, M.J., Damonte, E.B., Ray, B. 2002. Isolation, chemical investigation and antiviral activity of polysaccharide from Gracilaria corticata (Gracilariaceae, Rhodophyta). International Journal of Biological Macromolecules 31:87-95.

Melo, M.R.S., Feitosa, J.P.A., Freitas, A.L.P., de Paula, R.C.M. 2002. Isolation and characterization of soluble sulfated polysaccharide from the red seaweed Gracilaria cornea. Carbohydrate Polymers 49:491-498.

Meena, D.K., Das, P., Kumar, S., Mandal, S.C., Prusty, A.K., Singh, S.K., Akhtar, M.S., Behera, B.K., Kumar, K., Pal, A.K., Mukherjee, S.C. 2013. Beta-glucan: an ideal immunostimulant in aquaculture (a review). Fish Physiology and Biochemistry 39:431-457.

Sakai, M. Current research status of fish immunostimulants. 1999. Aquaculture 172:63-92.

Samocha, T.M., Davis, D.A., Saoud, I.P., DeBault, K. 2004. Substitution of fish meal by co-extruded soybean poultry byproduct meal in practical diets for the Pacific white shrimp, Litopenaeus vannamei. Aquaculture 231:197-203.

Saraswaty, V., Mozef, T., Risdian, C., Rasyid, A. 2015. Bioactivity of polysaccharide from Gracilaria verrucosa as $\alpha$ Glucosidase inhibitor. Procedia Chemistry 16: 687-693

Sivagnanavelmurugan, M., Thaddaeus, B.J., Palavesam, A., Immanuel, G. 2014. Dietary effect of Sargassum wightii fucoidan to enhance growth, prophenoloxidase gene expression of Penaeus monodon and immune resistance to Vibrio parahaemolyticus. Fish \&Shellfish Immunology 39:429-449.

Souza, B.W.S., Cerguiera, M.A., Bourbon, A.I., Pinheiro, A.C., Martins, J.T., Teixeira, J.A., Coimbra, M.A., Vicente, A.A. 2012. Chemical characterization and antioxidant activity of sulfated polysaccharide from the red seaweed Gracilaria birdiae. Food Hydrocolloids 27: 287-292.

Sritunyalucksana, K., Söderhäll, K. 2000. The proPO and clotting system in crustaceans. Aquaculture 191:53-69. 
Tayag, C., Lin, Y-C., Li, C-C., Liou, C-H., Chen, J-C. 2010. Administration of the hot water of Spirulina platensis enhanced the immune response of white shrimp Litopenaeus vannamei and its resistance against Vibrio alginolyticus. Fish \&Shellfish Immunology 28: 764773.

Wongprasert, K., Rudtanatip, T., Praiboon, J. 2014. Immunostimulatory activity of sulfated galactans isolated from the red seaweed Gracilaria fisheri and development of resistance against white spot syndrome virus (WSSV) in shrimp. Fish \&Shellfish Immunology 36:52-60.

Yeh, S.T., Chen, J.C. 2008. Immunomodulation by carrageenans in the white shrimp Litopenaeus vannamei and its resistance against Vibrio alginolyticus. Aquaculture276:22-28.

Yeh, S.T., Chen, J.C. 2009. White shrimp Litopenaeus vannamei that received the hot water extract of Gracilaria tenuistipitata showed earlier recovery in immunity after a Vibrio alginolyticus injection. Fish\&Shellfish Immunology 26:724-730.

Yun, B., Ai, Q., Mai, K., Xu, M., Qi, G., Luo, Y. 2012. Synergistic effects of dietary cholesterol and taurine on growth performance and cholesterol metabolism in juvenile turbot (Scophthalmus maximusL.) fed high plant protein diets. Aquaculture324-325:85-91. 